Note: This article will be published in a forthcoming issue of the International Journal of Sport Nutrition and Exercise Metabolism. This article appears here in its accepted, peerreviewed form; it has not been copyedited, proofed, or formatted by the publisher.

Section: Original Research

Article Title: Extreme Rapid Weight Loss and Rapid Weight Gain Observed in UK Mixed Martial Arts Athletes Preparing for Competition

Authors: Joseph John Matthews ${ }^{1}$ and Ceri Nicholas ${ }^{2}$

Affiliations: ${ }^{1}$ School of Sport and Creative Services, University College Birmingham, Birmingham, West Midlands, United Kingdom. ${ }^{2}$ Department of Clinical Sciences and Nutrition, University of Chester, Chester, Cheshire, United Kingdom.

Running Head: RWL and RWG in Mixed Martial Arts

Journal: International Journal of Sport Nutrition and Exercise

Acceptance Date: September 4, 2016

(C)2016 Human Kinetics, Inc.

DOI: http://dx.doi.org/10.1123/ijsnem.2016-0174 


\title{
Extreme rapid weight loss and rapid weight gain observed in UK mixed martial arts athletes preparing for competition
}

\author{
Running Head: RWL and RWG in Mixed Martial Arts \\ Joseph John Matthews \\ University College Birmingham
}

Address: School of Sport and Creative Services, University College Birmingham, Summer Row, Birmingham, West Midlands, B3 1JB, United Kingdom.

\author{
Ceri Nicholas \\ University of Chester
}

Address: Department of Clinical Sciences and Nutrition, University of Chester, Parkgate Road, Chester, Cheshire, CH1 4BJ, United Kingdom. 
"Extreme Rapid Weight Loss and Rapid Weight Gain Observed in UK Mixed Martial Arts Athletes Preparing for Competition" by Matthews JJ, Nicholas C

International Journal of Sport Nutrition and Exercise Metabolism

(C) 2016 Human Kinetics, Inc.

\section{Abstract}

There is a lack of research documenting the weight-making practices of mixed-martialarts (MMA) competitors. The purpose of the investigation was to quantify the magnitude and identify the methods of rapid weight loss (RWL) and rapid weight gain (RWG) in MMA athletes preparing for competition. Seven athletes (mean \pm SD, age $24.6 \pm 3.5 \mathrm{yrs}$, body mass $69.9 \pm 5.7 \mathrm{~kg}$, competitive experience $3.1 \pm 2.2 \mathrm{yrs}$ ) participated in a repeated-measures design. Measures of dietary intake, urinary hydration status, and body mass were recorded in the week preceding competition. Body mass decreased significantly $(p<0.0005)$ from baseline by $5.6 \pm 1.4 \mathrm{~kg}(8 \pm$ $1.8 \%$ ). During the RWG period (32 \pm 1 hours) body mass increased significantly $(p<0.001)$ by $7.4 \pm 2.8 \mathrm{~kg}(11.7 \pm 4.7 \%)$, exceeding RWL. Mean energy and carbohydrate intake were $3176 \pm 482 \mathrm{kcal}^{- \text {day }^{-1}}$ and $471 \pm 124 \mathrm{~g} \cdot \mathrm{day}^{-1}$, respectively. At the official weigh-in $57 \%$ of athletes were dehydrated $\left(1033 \pm 19 \mathrm{mOsmol} \cdot \mathrm{kg}^{-1}\right)$ and the remaining $43 \%$ were severely dehydrated $\left(1267 \pm 47 \mathrm{mOsmol} \cdot \mathrm{kg}^{-1}\right)$. Athletes reported using harmful dehydration-based RWL strategies, including sauna (43\%) and training in plastic suits (43\%). Results demonstrated RWG greater than RWL, this is a novel finding and may be attributable to the 32 hour duration from weigh-in till competition. The observed magnitude of RWL and strategies used are comparable to those which have previously resulted in fatalities. Rule changes which make RWL impractical should be implemented with immediate effect to ensure the health, safety and wellbeing of competitors.

Keywords: Dehydration, Combat Sport, Water Loading, Making Weight, MMA 
"Extreme Rapid Weight Loss and Rapid Weight Gain Observed in UK Mixed Martial Arts Athletes Preparing for Competition" by Matthews JJ, Nicholas C

International Journal of Sport Nutrition and Exercise Metabolism

(C) 2016 Human Kinetics, Inc.

\section{Introduction}

Mixed-martial-arts (MMA) is one of the fastest growing sports in the world (Ko et al., 2010). It encompasses combat styles derived from various martial arts, which involve striking, grappling, wrestling and submission techniques (La Bounty et al., 2011). Like other combat sports, MMA athletes are required to compete in a specific weight category. However, many athletes undergo a process of making-weight, characterized by rapid weight loss (RWL) and subsequent rapid weight gain (RWG), in order to gain a size and/or strength advantage over their opponent (Franchini et al., 2012).

A recent paper has called for RWL to be banned in combat sports as it violates the World Anti-Doping Agency (WADA) code (Artioli et al., 2016). Specifically, RWL has the potential to enhance sports performance; is a potential health risk to the athlete; and violates the spirit of the sport. Research from judo and wrestling supports this notion (Artioli et al., 2010a; Wroble \& Moxley, 1998a; 1998b). Although, research investigating the weight-making practices of MMA athletes is lacking.

There are immediate concerns with the RWL process in MMA. In 2013, a Brazilian MMA athlete was found dead in a sauna, undergoing RWL, the day before competition (Crighton et al., 2015). More recently, a Chinese MMA athlete suffered fatal acute myocardial infarction as a result of dehydration-induced RWL (Thomas, 2015). Following the latest death, ONE Championship announced a new compulsory weigh-in program which banned weight-cutting by dehydration (ONE Championship, 2015). This is a significant step forward in ensuring the health and safety of MMA athletes in competition. Other regulatory bodies have not followed these guidelines. The Ultimate Fighting Championship (UFC) have recently extended the duration available for RWG from approximately 24 hours to 32 hours in order to allow athletes 
"Extreme Rapid Weight Loss and Rapid Weight Gain Observed in UK Mixed Martial Arts Athletes Preparing for Competition" by Matthews JJ, Nicholas C

International Journal of Sport Nutrition and Exercise Metabolism

(C) 2016 Human Kinetics, Inc.

more time to recover (Raimondi, 2016). This decision may be detrimental and is not supported by existing evidence. Conversely, athletes typically practice more aggressive RWL when a longer window for RWG is permitted (Alderman et al., 2004; Oppliger et al., 2003).

The limited research in MMA suggests athletes engage in RWL and RWG similar to other combat sports (Coswig et al., 2015; Jetton et al., 2013). However, RWL has not been objectively measured in an MMA population and the methods used to elicit RWL in MMA are unknown. This does not provide regulatory bodies with the information to produce evidence-based weight-making guidelines. Therefore, the aim of the present study was to quantify the magnitude and identify the methods of RWL and RWG in MMA athletes preparing for competition.

\section{Methods}

This was an observational, cross-sectional study with a repeated-measures design. Data were collected during three official competitive MMA events, with prior permission from the event organizers. Data collection spanned a seven-day period ending approximately 1-hour prior to competition (figure 1). The study was approved by the University of Chester, Faculty of Life Sciences Research Ethics Committee.

Seven male MMA athletes were recruited for the study, via convenience sampling, from a single gymnasium in the South of England (table 1). In order to compete in MMA, athletes are required to undergo a medical prior to competition to ensure their safety, thus all participants were assumed healthy. Participants were required to have a minimum of one-year competitive experience and have competed in a minimum of two sanctioned MMA bouts in order to be eligible for inclusion. Athletes competing in the heavyweight category were excluded from the study, as 
"Extreme Rapid Weight Loss and Rapid Weight Gain Observed in UK Mixed Martial Arts Athletes Preparing for Competition" by Matthews JJ, Nicholas C

International Journal of Sport Nutrition and Exercise Metabolism

(C) 2016 Human Kinetics, Inc.

heavyweights typically do not engage in RWL before competition (Artioli et al., 2010a). All participants gave written informed consent to be eligible for inclusion.

\section{Procedures}

Body mass was recorded using calibrated scales (Seca 880 Digital Floor Scale, Seca: UK). Baseline body mass was recorded seven-days before competition, nude, upon waking, after morning void (figure 1). Official competition weigh-ins were recorded nude between 12:00-13:00 on the day before competition. The final body mass was recorded $\sim 1$-hour pre-competition. Prior to competition, each participant's clothing were weighed separately and subtracted from the final body mass to provide a nude-equivalent value. This was a methodological advantage as athletes were weighed close to competing, giving a better representation of competition body mass.

Urine samples were collected immediately prior to body mass (figure 1). Participants were required to take a mid-flow urine sample collected in $5 \mathrm{ml}$ containers. Samples were measured for urine osmolality ( $\left.\cup_{\text {osm }}\right)$ using a portable refractive index osmometer (Osmocheck, Vitech Scientific Ltd: UK). The osmometer was calibrated prior to each test. Once samples were analysed they were immediately discarded. This field-based method of urinalysis has been validated against freeze point depression osmometry with a coefficient of variation of $0 \%$ at physiologically meaningful concentrations (Sparks \& Close, 2013). Urine osmolality $\leq 700 \mathrm{mOsmol} \cdot \mathrm{kg}^{-}$ 1 was taken as indication of being euhydrated (Sawka et al., 2007). Overall, four categories were used to classify hydration status: 0 to $249 \mathrm{mOsmol} \cdot \mathrm{kg}^{-1}$ (hyperhydrated), 250 to $700 \mathrm{mOsmol} \cdot \mathrm{kg}^{-1}$ (euhydrated), 701 to $1080 \mathrm{mOsmol} \cdot \mathrm{kg}^{-1}$ (dehydrated), and 1081 to $1500 \mathrm{mOsmol} \cdot \mathrm{kg}^{-1}$ (severely dehydrated), as previously described in elite combat sport athletes (Fernandez-Elias et al., 2014). 
"Extreme Rapid Weight Loss and Rapid Weight Gain Observed in UK Mixed Martial Arts Athletes Preparing for Competition" by Matthews JJ, Nicholas C

International Journal of Sport Nutrition and Exercise Metabolism

(C) 2016 Human Kinetics, Inc.

Values for nutrient and fluid intakes were obtained from a seven-day weighed food record (WFR) using calibrated scales (Salter 305 food scales, Salter: UK). The seven-day WFR has been previously used for the dietary assessment of athletes (Beis et al., 2011). Food records were kept for the entire study duration, which concluded when the final body mass was recorded. All athletes were instructed to prepare for competition habitually. Participants received detailed verbal and written instructions on how to record food and fluid intakes. All leftovers were described and weighed. In the event that participants were not able to weigh their food and/or fluid they were instructed to give as much information as possible. Any questions regarding the type and the amount of food and fluid consumed were resolved via direct interviews. Energy and nutrient intakes were calculated using the professional dietary analysis software Nutritics® (Nutritics Ltd., Ireland).

The RWL questionnaire (RWLQ) quantified the methods used to elicit RWL for competition. The questionnaire was developed based on field experience and adapted from a similar model validated in other combat sports (Artioli et al., 2010c; Brito et al., 2012). Participants completed the questionnaire during the RWG period and gave responses based on all RWL strategies used throughout their competitive career.

\section{Statistical Analyses}

Analyses were conducted using Microsoft Exce ${ }^{\circledR} 14.0$ (Version 14.4.8 for Mac 2011, Microsoft Corporation) and SPSS ${ }^{\circledR} 22.0$ (Version 22.0 for Mac, SPSS Inc., Chicago, IL). The Shapiro-Wilk test assessed normal distribution of the data. Carbohydrate intake during RWL violated the assumption of normality $(p<0.001)$ and was treated as non-parametric data. Body mass and $U_{\text {osm }}$ were analysed using a within-subjects ANOVA. The Greenhouse-Geisser procedure corrected the degrees 
"Extreme Rapid Weight Loss and Rapid Weight Gain Observed in UK Mixed Martial Arts Athletes Preparing for Competition" by Matthews JJ, Nicholas C

International Journal of Sport Nutrition and Exercise Metabolism

(C) 2016 Human Kinetics, Inc.

of freedom of the F-distribution for body mass as it violated the assumption of sphericity $(p=0.048)$. Post-hoc pairwise comparisons were performed. This included a Bonferroni-type adjustment to the alpha level to minimize the possibility of incurring a type I error. The conservative approach to data analysis was taken due to the small sample size. Energy and carbohydrate intake during RWL and RWG were investigated using a paired t-test and a Wilcoxon signed ranks test. All data was ratio and presented as mean \pm standard deviation (SD). Statistical significance was set at $p<0.05$ for all variables.

\section{Results}

Duration from the official weigh-in to competition was $32 \pm 1$ hours. Final body mass and $U_{\text {osm }}$ were recorded $45 \pm 31$ minutes pre-competition. A significant time effect was found for changes in body mass $\left(F_{(1.175)}=45.434, p<0.0005\right)$. Pairwise comparisons identified a significant decrease $(p<0.0005)$ in body mass of $5.6 \pm 1.4 \mathrm{~kg}$ $(8.0 \pm 1.8 \%$ total body mass) during RWL, and a significant increase $(p<0.001)$ of 7.4 $\pm 2.8 \mathrm{~kg}(11.7 \pm 4.7 \%$ total body mass) during the RWG period (figure 2$)$. Precompetition body mass $(71.8 \pm 5.4 \mathrm{~kg})$ was higher than baseline body mass $(69.9 \pm$ $5.7 \mathrm{~kg}$ ). The greatest absolute and relative change was from a single participant who experienced RWL of $7.5 \mathrm{~kg}(10.8 \%)$ and RWG of $12.7 \mathrm{~kg}(20.6 \%)$.

A significant time effect was found for changes in $U_{o s m}\left(F_{(2)}=31.803\right.$, $p<0.0005)$. Urine osmolality significantly increased $(p=0.019)$ from baseline to the official weigh-in and significantly decreased $(p<0.001)$ from the official weigh-in to precompetition. At the official weigh-in, $57 \%$ of athletes were classified as dehydrated $\left(1033 \pm 19 \mathrm{mOsmol} \mathrm{kg}^{-1}\right)$ and the remaining $43 \%$ were classified as severely dehydrated $\left(1267 \pm 47 \mathrm{mOsmol} \cdot \mathrm{kg}^{-1}\right)$. When measured pre-competition $57 \%$ of 
"Extreme Rapid Weight Loss and Rapid Weight Gain Observed in UK Mixed Martial Arts Athletes Preparing for Competition" by Matthews JJ, Nicholas C

International Journal of Sport Nutrition and Exercise Metabolism

(c) 2016 Human Kinetics, Inc.

athletes exhibited hyperhydration (108 $\left.\pm 38 \mathrm{mOsmol} \cdot \mathrm{kg}^{-1}\right), 29 \%$ were euhydrated, and $14 \%$ remained dehydrated $\left(930 \mathrm{mOsmol} \cdot \mathrm{kg}^{-1}\right)$.

Dietary assessment data was available for six of the seven athletes due to one athlete reporting a lost food diary following study completion. Energy intake increased significantly $(p=0.005)$ from $1261 \pm 725 \mathrm{kcal} \cdot$ day $^{-1}$ during RWL to $3176 \pm 482 \mathrm{kcal} \cdot \mathrm{day}^{-}$ 1 during RWG (figure 3). Absolute carbohydrate intake increased significantly $(p=0.028)$ from $68 \pm 82 \mathrm{~g} \cdot$ day $^{-1}$ during $R W L$ to $471 \pm 124 \mathrm{~g} \cdot$ day $^{-1}$ during RWG (figure 3). Relative carbohydrate intake increased from $1 \pm 1.2 \mathrm{~g} \cdot \mathrm{kg}$ day $^{-1}$ during RWL to 7.2 $\pm 1.9 \mathrm{~g} \cdot \mathrm{kg}^{\mathrm{day}}{ }^{-1}$ during RWG. For carbohydrate intake during RWL one athlete skewed the data with absolute and relative intakes of $234 \mathrm{~g} \cdot \mathrm{day}^{-1}$ and $3.4 \mathrm{~g} \cdot \mathrm{kg}^{\mathrm{day}}{ }^{-1}$, respectively. Water and sodium intake decreased throughout the RWL period (figure 4). Frequency analysis of the RWLQ identified a high prevalence of participants engaging in RWL procedures (table 2).

\section{Discussion}

The aim of the present study was to quantify the magnitude and methods of RWL and RWG in MMA athletes preparing for competition. The main findings demonstrate that all athletes underwent extreme RWL and RWG, using harmful dehydration strategies. Furthermore, all athletes either equaled or exceeded their baseline body mass when measured pre-competition.

The magnitude of observed RWL $(5.6 \pm 1.4 \mathrm{~kg})$ was greater than other reported RWL in Brazilian jiu-jitsu, karate, and taekwondo athletes (Brito et al., 2012), Brazilian judokas (Artioli et al., 2010a), French judokas (Filaire et al., 2001), and Iranian wrestlers (Kordi et al., 2011). This may be attributable to the longer recovery period in the present study, which leads athletes to practice more aggressive RWL. However, 
"Extreme Rapid Weight Loss and Rapid Weight Gain Observed in UK Mixed Martial Arts Athletes Preparing for Competition" by Matthews JJ, Nicholas C

International Journal of Sport Nutrition and Exercise Metabolism

(C) 2016 Human Kinetics, Inc.

RWL was lower than previously reported $(7.4 \pm 1.1 \mathrm{~kg})$ in a small group of MMA athletes with a 24-hour recovery period (Coswig et al., 2015). It is possible that this difference was due to the larger starting body mass of participants in the previous study. Moreover, the self-report RWL may have led athletes to overestimate their weight loss. Interestingly, in the Coswig et al. (2015) study, a group of MMA athletes weighed in $\sim 30$ minutes before competition and did not engage in RWL. Athletes who did not engage in RWL also has significantly higher glucose availability and significantly lower markers of muscle damage than those engaging in RWL (Coswig et al., 2015). This suggests that holding the weigh-in closer to competition results in abstinence from RWL in MMA athletes.

Only one study has previously recorded RWG in MMA athletes. Jetton et al. (2013) observed RWG of $3.4 \pm 2.2 \mathrm{~kg}(4.4 \%)$ with 22-hours from weigh-in to competition. These results are similar to reports in wrestlers with a 20-hour recovery window (Scott et al., 1994). However, a markedly greater magnitude of $7.4 \pm 2.8 \mathrm{~kg}$ $(11.7 \pm 4.7 \%)$ was recorded during RWG in the present study with a 32-hour duration post weigh-in. This magnitude of RWG creates an unfair match-up if the opposing competitor does not engage in RWL and RWG. The athlete with the greatest weight manipulation competed three weight-classes heavier than his official weigh-in weight (bantamweight to welterweight). This has the potential to enhance performance when considering power to weight ratio of the athletes, and violates the 'spirit of the sport' during competition (Artioli et al., 2016).

The increased RWG observed was attributable to food and fluid intakes during the 32-hour recovery period. Dietary analysis showed high relative carbohydrate intake $7.2 \pm 1.9 \mathrm{~g} \cdot \mathrm{kg} \cdot \mathrm{day}^{-1}$ during RWG, consistent with guidelines for maximizing glycogen resynthesis (Burke et al., 2011). Carbohydrate intake was substantially 
"Extreme Rapid Weight Loss and Rapid Weight Gain Observed in UK Mixed Martial Arts Athletes Preparing for Competition" by Matthews JJ, Nicholas C

International Journal of Sport Nutrition and Exercise Metabolism

(C) 2016 Human Kinetics, Inc.

higher than previous controlled studies where athletes were allowed to recover and rehydrate ad libitum following RWL of $\geq 5 \%$ body mass (Artioli et al., 2010b; Fogelholm et al., 1993; Sagayama et al., 2014). Artioli et al. (2010b) observed RWG equivalent to $51 \%$ of body mass losses during 4 -hours of recovery with a mean carbohydrate intake of $201 \mathrm{~g}$. Moreover, a recovery window of 5 -hours with a larger carbohydrate intake of $285 \pm 27 \mathrm{~g}$ were able to restore $73 \%$ of $\mathrm{RWL}$ in wrestlers and judokas (Fogelholm et al., 1993). Sagayama et al. (2014) demonstrated restoration of 70\% body mass losses (RWL $6.0 \pm 0.9 \%$ ) during a 12-hour recovery period. During recovery total energy and carbohydrate intake was $3066 \pm 506 \mathrm{kcal}$ and $396 \pm 81 \mathrm{~g}$, respectively. Changes in stored glycogen explain some of the manipulation of body mass. All athletes, except one, followed a very low-carbohydrate diet $\left(\leq 50 \mathrm{~g} \cdot \mathrm{day}^{-1}\right)$ during RWL which would have resulted in glycogen depletion. High carbohydrate intakes during RWG increase glycogen storage and its associated three-four parts water weight (Kreitzman et al., 1992).

Athletes reported using a range of dehydration-based RWL techniques throughout their competitive careers (table 2). Concerningly, all athletes reported using sauna and training in plastic suits, although $29 \%$ stated that they did not use these methods anymore. This prevalence is substantially higher than in judo (Artioli et al., 2010a), jujitsu, karate and taekwondo (Brito et al., 2012). This suggests MMA athletes practice more aggressive RWL strategies than other combat sports, in addition to experiencing greater RWL overall. Both sauna use and training in plastic suits have been implicated in previous combat sport fatalities and should be regarded as harmful RWL methods. Dehydration-induced RWL was confirmed with urinalysis showing $57 \%$ of athletes were dehydrated (1033 $\left.\pm 19 \mathrm{mOsmol} \cdot \mathrm{kg}^{-1}\right)$ and the remaining $43 \%$ were severely dehydrated $\left(1267 \pm 47 \mathrm{mOsmol} \cdot \mathrm{kg}^{-1}\right)$ at the official weigh-in. This is consistent 
"Extreme Rapid Weight Loss and Rapid Weight Gain Observed in UK Mixed Martial Arts Athletes Preparing for Competition" by Matthews JJ, Nicholas C

International Journal of Sport Nutrition and Exercise Metabolism

(C) 2016 Human Kinetics, Inc.

with Jetton et al. (2013) who identified a high prevalence of significant dehydration, which persisted when athletes were measured 2-hours pre-competition. It is recommended that weight-cutting by dehydration be prohibited from use in making weight for competition.

A recent editorial reported the use of water loading $(W L)$ as a RWL method in $67 \%$ of MMA athletes (Crighton et al., 2015). This is similar to the present study, which found $57 \%$ using WL to elicit RWL. This was identified objectively by the gradual decrease in water intake throughout the RWL period from $6511 \pm 1138 \mathrm{ml} \cdot$ day $^{-1}$ sixdays pre-competition compared to $1269 \pm 625 \mathrm{ml} \cdot \mathrm{day}^{-1}$ on the day before official weigh-in (figure 4). Athletes believe manipulation of water and sodium intake creates a 'flushing effect', termed water diuresis, that induces excessive urine production. The effects of WL on voluntary body mass manipulation have not been explored. However, an early study by Shore et al. (1988) found arginine vasopressin (AVP) decreased significantly following three-days of a WL protocol similar to the present study $(6.8$ $L \cdot$ day $\left.^{-1}\right)$. It may be hypothesised that this suppression of AVP could create a diuresis when water intake is immediately restricted following WL. This may be explained by down regulation of aquaporin-2 channels in the collecting duct of the nephrons (Kwon et al., 2013). The practice of WL has not previously been reported in any other combat sport and requires further investigation.

There are concerns for the immediate health of athletes undergoing RWL. The largest RWL in the present study was $10.8 \%(7.5 \mathrm{~kg})$, comparable to that which resulted in the hyperthermia-related deaths of three collegiate wrestlers in 1997 (CDC, 1998). Following the deaths, the NCAA revised their guidelines governing RWL practices and weigh-in procedures (NCAA, 1998). The NCAA now prohibits the use of dehydration RWL methods and artificial rehydration techniques. In addition, all weigh- 
"Extreme Rapid Weight Loss and Rapid Weight Gain Observed in UK Mixed Martial Arts Athletes Preparing for Competition" by Matthews JJ, Nicholas C

International Journal of Sport Nutrition and Exercise Metabolism

(C) 2016 Human Kinetics, Inc.

ins must be held $\leq 2$ hours before the beginning of competition. A review of the NCAA rule change concluded that the weight-management program had a significant positive influence on athlete's weight control behavior (Oppliger et al., 2006). Recent rule changes by MMA organization ONE Championship prevent athletes from dropping a weight class when $\leq 8$ weeks out from competition, and final competition weigh-ins are now held three hours prior to the event (ONE Championship, 2015). Both the NCAA and ONE Championship also require each athlete to pass a urine specific gravity check at weigh-in to prevent dehydration-induced RWL. The present study supports these weight-management guidelines and echoes recent calls for RWL to be banned in MMA and other combat sports (Artioli et al., 2016). Voluntary education programs to reduce RWL have been unsuccessful (Steen \& Brownell, 1990). The only way to prevent harmful RWL is to implement rules that make RWL impractical (Khodaee et al., 2015). This has been effectively demonstrated by the NCAA and ONE Championship. The UFC and other leading organizations must act immediately to protect the health of athletes.

The present study is limited by the small sample size, which reduces the ability to extrapolate these results to a wider MMA population. It should be noted that results of the present study are specific to the 32-hour recovery period and may not be transferable to events that allow for a shorter recovery period. Although evidence suggests that the majority of RWL occurs in the final week before competition, the seven-day period used in the present study may not have captured all of the RWL that athletes underwent for competition. 
"Extreme Rapid Weight Loss and Rapid Weight Gain Observed in UK Mixed Martial Arts Athletes Preparing for Competition" by Matthews JJ, Nicholas C

International Journal of Sport Nutrition and Exercise Metabolism

(c) 2016 Human Kinetics, Inc.

\section{Summary and Practical Applications}

This is the first study to demonstrate that MMA athletes engage in extreme RWL and RWG practices when preparing for competition. A novel finding was that all athletes were able to equal or exceed baseline measures of body mass during the RWG period, with one athlete competing three weight-classes heavier than his official weigh-in weight. This creates unsafe competition and violates the spirit of the sport. The magnitude and methods of RWL are comparable to those associated with previous fatalities. We suggest that the observed 32-hour recovery window promotes aggressive weight-making practices and poses an immediate risk to athlete's health. Safe weight-management guidelines have employed shorter recovery periods $(\leq 3$ hours) and banned RWL by dehydration. Global MMA weigh-in regulations should be addressed with immediate effect to ensure the health, safety and wellbeing of competitors.

\section{Acknowledgements}

The authors would like to thank all of the participants who gave their time for the study. As well as the gymnasium that supported testing at their events and their understanding of the need for more research in the field. A special thank you to Sam Blacker at the University of Chichester for providing support and allowing the use of testing equipment for data collection. 
"Extreme Rapid Weight Loss and Rapid Weight Gain Observed in UK Mixed Martial Arts Athletes Preparing for Competition" by Matthews JJ, Nicholas C

International Journal of Sport Nutrition and Exercise Metabolism

(C) 2016 Human Kinetics, Inc.

\section{Authorships}

The study was designed by JM and CN; data were collected and analysed by JM; data interpretation and manuscript preparation were undertaken by $\mathrm{JM}$ and $\mathrm{CN}$. Both authors approved the final version of the paper.

\section{Conflicts of Interest}

The authors state no conflicts of interest. 
"Extreme Rapid Weight Loss and Rapid Weight Gain Observed in UK Mixed Martial Arts Athletes Preparing for Competition" by Matthews JJ, Nicholas C

International Journal of Sport Nutrition and Exercise Metabolism

(C) 2016 Human Kinetics, Inc.

\section{References}

Alderman, B.L., Landers, D.M., Carlson, J., \& Scott, J.R. (2004). Factors related to rapid weight loss practices among international-style wrestlers. Medicine and Science in Sport and Exercise, 36(2), 249-252.

Artioli, G.G., Gualano, B., Franchini, E., Scagliusi, F.B., Takesian, M., Fuchs, M., \& Lancha, A.H.L. (2010a). Prevalence, magnitude, and methods of rapid weight loss among judo competitors. Medicine and Science in Sports and Exercise, 42(3), 436-442.

Artioli, G.G., Iglesias, R.T., Franchini, E., Gualano, B., Kashiwagura, D.B., ... Junior, A.H.L. (2010b). Rapid weight loss followed by recovery time does not affect judo-related performance. Journal of Sport Sciences, 28(1), 21-32.

Artioli, G.G., Saunders, B., Iglesias, R.T., \& Franchini, E. (2016). It is time to ban rapid weight loss from combat sports. Sports Medicine, 1-6. DOI 10.1007/s40279016-0541-x.

Artioli, G.G., Scagliusi, F., Kashiwagura, D., Franchini, E., Gualano, B., \& Junior, A.H.L. (2010c). Development, validity and reliability of a questionnaire designed to evaluate rapid weight loss patterns in judo players. Scandinavian Journal of Medicine and Science in Sports, 20(1), e177-e187. Doi: 10.1111/j.16000838.2009.00940.x

Beis, L.Y., Willkomm, L., Ross, R., Bekele, Z., Wolde, B., Fudge, B., \& Pitsiladis, Y.P. (2011). Food and macronutrient intake of elite Ethiopian distance runners. Journal of the International Society of Sports Nutrition, 8, 7.

Brito, C.J., Roas, A.F.C.M., Brito, I.S.S., Marins, J.C.B., Cordova, C., \& Franchini, E. (2012). Methods of body-mass reduction by combat sport athletes. International Journal of Sport Nutrition and Exercise Metabolism, 22, 89-97.

Burke, L. M., Hawley, J. A., Wong, S. H., \& Jeukendrup, A. E. (2011). Carbohydrates for training and competition. Journal of Sports Sciences, 29(1), S17-S27.

Centers for Disease Control and Prevention [CDC] (1998). Hyperthermia and dehydration-related deaths associated with intentional rapid weight loss in three collegiate wrestlers-North Carolina, Wisconsin, and Michigan, NovemberDecember 1997. Morbidity and Mortality Weekly Report, 47(6), 105-107.

Coswig, V.S., Fukuda, D.H., \& Del Vecchio, F.B. (2015). Rapid weight loss elicits harmful biochemical and hormonal responses in mixed martial arts athletes. International Journal of Sport Nutrition and Exercise Metabolism, 25, 480-486.

Crighton, B., Close, G.L., \& Morton, J.P. (2015). Alarming weight cutting behaviours in mixed martial arts: a cause for concern and a call for action. British Journal of Sports Medicine, 0, 1-2. Doi: 10.1136/bjsports-2015-094732. 
"Extreme Rapid Weight Loss and Rapid Weight Gain Observed in UK Mixed Martial Arts Athletes Preparing for

Fernandez-Elias, V.E., Martinez-Abellan, A., Lopez-Gullon, J.M., Moran-Navarro, R., Pallares, J.G., Cruz-Sanchez, E.D., \& Mora-Rodriguez, R. (2014). Validity of hydration non-invasive indices during the weightcutting and official weigh-in for Olympic combat sports. PLOS ONE, 9(4), e95336. doi:10.1371/journal.pone.0095336.

Filaire, E., Maso, F., Degoutte, F., Jouanel, P., \& Lac, G. (2001). Food restriction, performance, psychological state and lipid values in judo athletes. International Journal of Sports Medicine, 22, 454-459.

Fogelholm, G.M., Koskinen, R., Laakso, J., Rankinen, T., \& Ruokonen, I. (1993). Gradual and rapid weight loss: effects on nutrition and performance in male athletes. Medicine and Science in Sport and Exercise, 25(3), 371-377.

Franchini, E., Brito, C.J., \& Artioli, G.G. (2012). Weight loss in combat sports: physiological, psychological and performance effects. Journal of the International Society of Sports Nutrition, 9, 52.

Jetton, A.M., Lawrence, M.M., Meucci, M., Haines, T.L., Collier, S.R., Morris, D.M., \& Utter, A.C. (2013). Dehdyration and acute weight gain in mixed martial arts fighters before competition. Journal of Strength and Conditioning Research, 27(5), 1322-1326.

Ko, Y., Kim, Y., \& Valacich, J. (2010). Martial arts participation: consumer motivation. International Journal of Sports Marketing and Sponsorship, 11(2), 105-123.

Khodaee, M., Olewinski, L., Shadgan, B., \& Kiningham, R.R. (2015). Rapid weight loss in sports with weight classes. Current Sports Medicine Reports, 14(6), 435-441.

Kordi, R., Ziaee, V., Rostami, M., \& Wallace W.A. (2011). Patterns of weight loss and supplement consumption of male wrestlers in Tehran. Sports Medicine, Arthroscopy, Rehabilitation, Therapy \& Technology, 3, 4. doi: 10.1186/17582555-3-4.

Kreitzman, S.N., Coxon, A.Y., \& Szaz, K.F. (1992). Glycogen storage: illusions of easy weight loss, excessive weight regain, and distortions in estimates of body composition. The American Journal of Clinical Nutrition, 56(1), 292S-293S.

Kwon, T.H., Frokiaer, J., \& Nielsen, S. (2013). Regulation of aquaporin-2 in the kidney: a molecular mechanism of body-water homeostasis. Kidney Research and Clinical Practice, 32(3), 96-102.

La Bounty, P., Campbell, B. I., Galvan, E., Cooke, M., \& Antonio, J. (2011). Strength and conditioning considerations for mixed martial arts. Strength and Conditioning Journal, 33(1), 56-67.

National Collegiate Athletic Association [NCAA] (1998). Immediate wrestling rules changes on weight. Overland Park, Kansas: National Collegiate Athletic Association. 
"Extreme Rapid Weight Loss and Rapid Weight Gain Observed in UK Mixed Martial Arts Athletes Preparing for

Competition" by Matthews JJ, Nicholas C

International Journal of Sport Nutrition and Exercise Metabolism

(C) 2016 Human Kinetics, Inc.

ONE Championship (2015). ONE Championship announces new weigh-in program. ONE Championship, viewed 2 August 2016, http://www.mmafighting.com/2015/12/11/9891100/one-championships-yangiian-bing-dies-from-weight-cutting.

Oppliger, R.A., Steen, S.A.N., \& Scott, J.R. (2003). Weight loss practices of college wrestlers. International Journal of Sport Nutrition and Exercise Metabolism, 13, 29-46.

Oppliger, R.A., Utter, A.C., Scott, J.R., Dick, R.W., \& Klossner, D. (2006). NCAA rule change improves weight loss among national championship wrestlers. Medicine and Science in Sports and Exercise, 38(5), 963-970.

Raimondi, M. (2016). Fighters participate in historic morning weigh-in before UFC 199. MMA Fighting, viewed 2 August 2016, http://www.mmafighting.com/2016/6/3/11856552/fighters-participate-inhistoric-earlier-weigh-in-before-ufc-199.

Sagayama, H., Yoshimura, E., Yamada, Y., Ichikawa, M., Ebine, N., ... Tanaka, H. (2014). Effects of rapid weight loss and regain on body composition and energy expenditure. Applied Physiology, Nutrition, and Metabolism, 39(1), 21-27.

Sawka, M.N., Burke, L.M., Elchner, E.R., Maughan, R.J., Montain, S.J., \& Stachenfeld, N.S. (2007). Exercise and fluid replacement. Medicine and Science in Sports and Exercise, 39(2), 377-390.

Scott, J.R., Horswill, C.A., \& Dick, R.W. (1994). Acute weight gain in collegiate wrestlers following a tournament weigh-in. Medicine and Science in Sports and Exercise, 26(9): 1181-1185.

Shore, A.C., Markandu, N.D., Sagnella, G.A., Singer, D.R.J., Forsling, M.L., Buckley, M.G., ... MacGregor, G.A. (1988). Endocrine and renal response to water loading and water restriction in normal man. Clinical Science, 75, 171-177.

Sparks, S.A., \& Close, G.L. (2013). Validity of a portable urine refractometer: the effects of sample freezing. Journal of Sport Sciences, 31(7), 745-749.

Steen, S.N., \& Brownell, K.D. (1990). Patterns of weight loss and regain in wrestlers: has the tradition changed? Medicine and Science in Sport and Exercise, 22, 762-768.

Thomas, L. (2015). ONE Championship's Yang Jian Bing dies from weight cutting complications. MMA Fighting, viewed 2 August 2016, http://www.mmafighting.com/2015/12/11/9891100/one-championships-yangjian-bing-dies-from-weight-cutting.

Wroble, R.R., \& Moxley, D.P. (1998a). Acute weight gain and its relationship to success in high school wrestlers. Medicine and Science in Sport and Exercise, 30(6), 949-951. 
"Extreme Rapid Weight Loss and Rapid Weight Gain Observed in UK Mixed Martial Arts Athletes Preparing for Competition" by Matthews JJ, Nicholas C

International Journal of Sport Nutrition and Exercise Metabolism

(c) 2016 Human Kinetics, Inc.

Wroble, R.R., \& Moxley, D.P. (1998b). Weight loss patterns and success rates in high school wrestlers. Medicine and Science in Sport and Exercise, 30(4), 625-628. 
"Extreme Rapid Weight Loss and Rapid Weight Gain Observed in UK Mixed Martial Arts Athletes Preparing for Competition" by Matthews JJ, Nicholas C

International Journal of Sport Nutrition and Exercise Metabolism

(C) 2016 Human Kinetics, Inc.

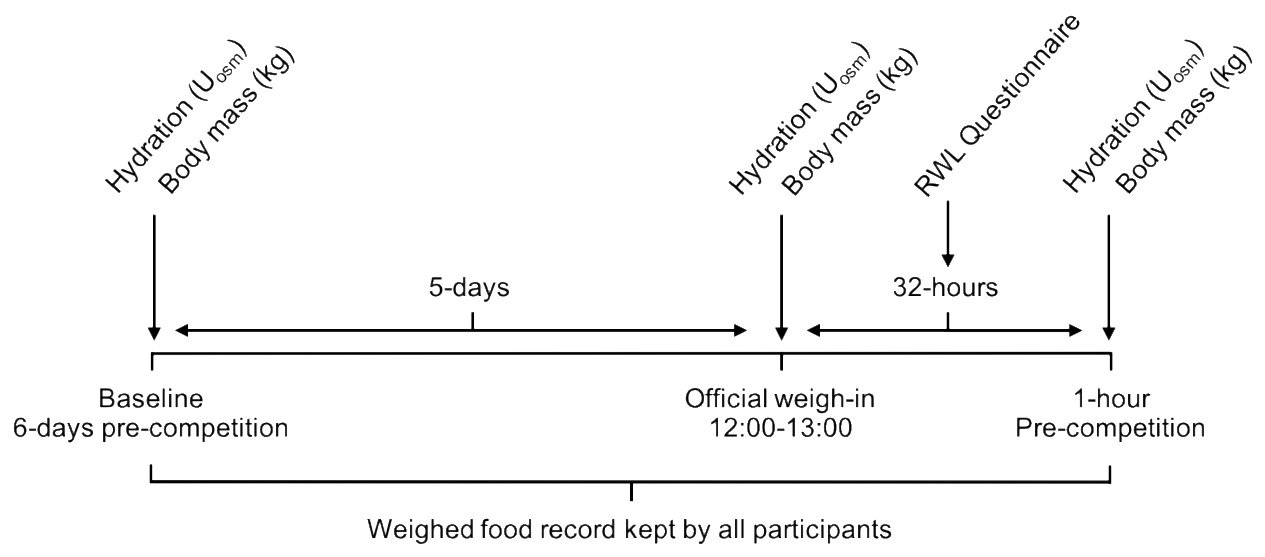

Figure 1. Overview of research design and data collection points. 
"Extreme Rapid Weight Loss and Rapid Weight Gain Observed in UK Mixed Martial Arts Athletes Preparing for Competition" by Matthews JJ, Nicholas C

International Journal of Sport Nutrition and Exercise Metabolism

(C) 2016 Human Kinetics, Inc.

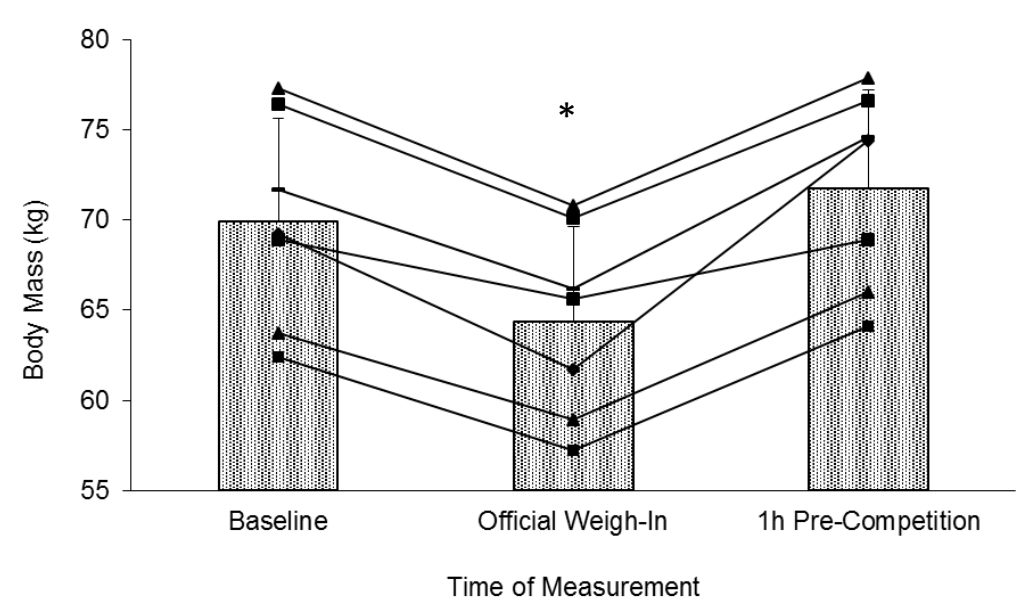

Figure 2. Changes in group and individual body mass throughout the week prior to competition. *Significantly different from the baseline measure, $\mathrm{p}<0.0005$. ${ }^{*}$ Significantly different from the official weigh-in, $p<0.005$. 
"Extreme Rapid Weight Loss and Rapid Weight Gain Observed in UK Mixed Martial Arts Athletes Preparing for Competition" by Matthews JJ, Nicholas C

International Journal of Sport Nutrition and Exercise Metabolism

(c) 2016 Human Kinetics, Inc.

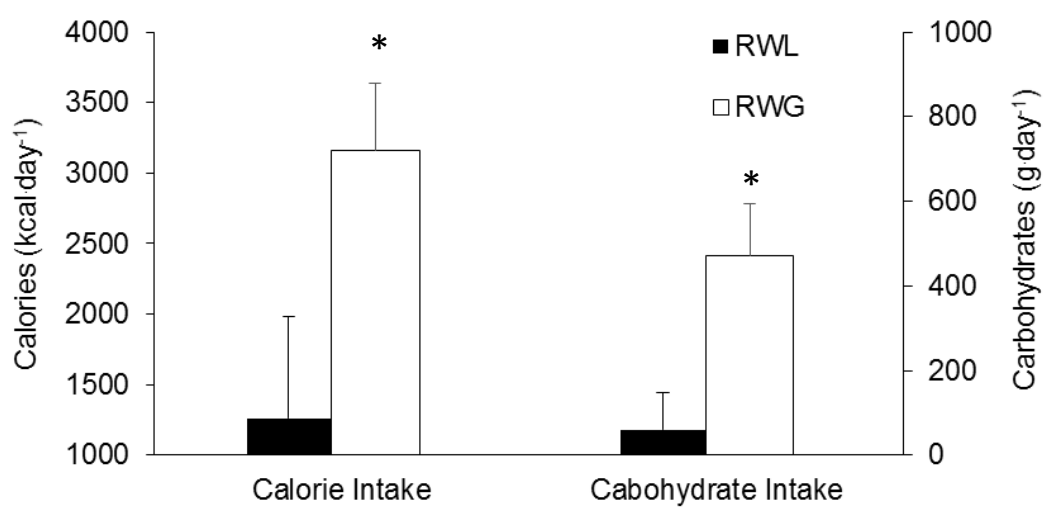

Figure 3. Comparisons of mean daily calorie and carbohydrate intake during the 5-day RWL period and the 2-day RWG period. *Significantly different from the RWL intake, $p<0.05$. 
"Extreme Rapid Weight Loss and Rapid Weight Gain Observed in UK Mixed Martial Arts Athletes Preparing for Competition" by Matthews JJ, Nicholas C

International Journal of Sport Nutrition and Exercise Metabolism

(C) 2016 Human Kinetics, Inc.

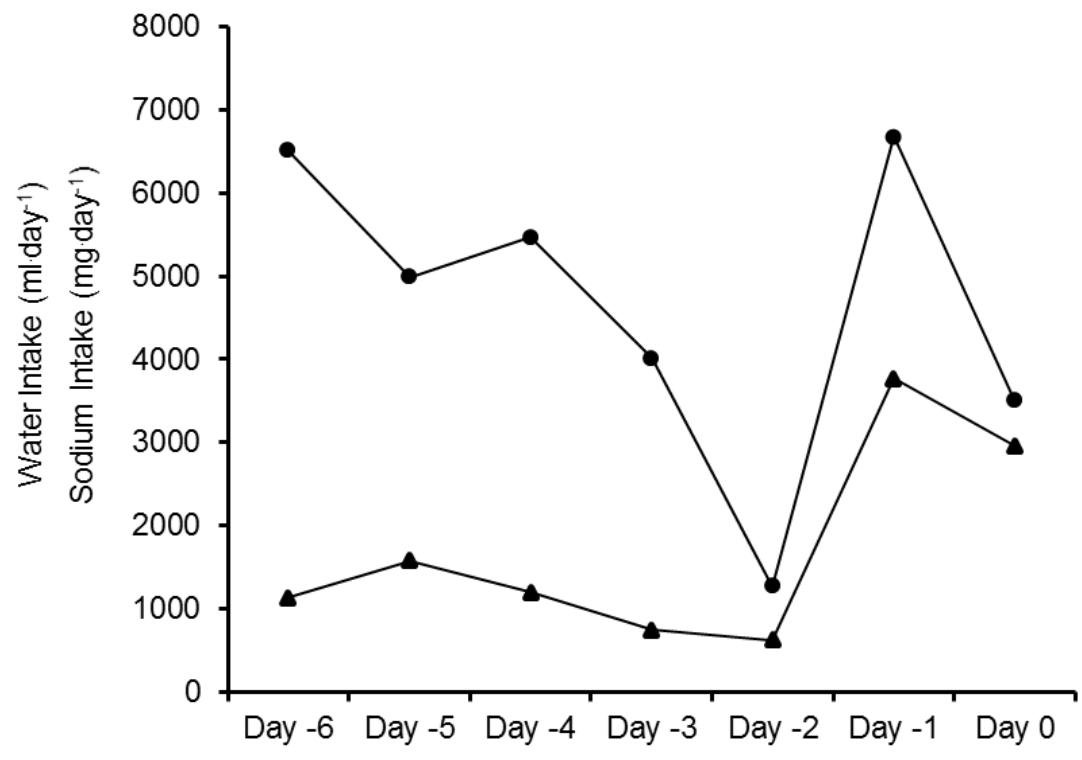

Figure 4. Daily changes in mean water intake $(\bullet)$ and sodium intake $(\mathbf{\Delta})$ throughout the week prior to competition. 
"Extreme Rapid Weight Loss and Rapid Weight Gain Observed in UK Mixed Martial Arts Athletes Preparing for Competition" by Matthews JJ, Nicholas C

International Journal of Sport Nutrition and Exercise Metabolism

(C) 2016 Human Kinetics, Inc.

Table 1. Group and individual participant baseline characteristics.

\begin{tabular}{cccccc}
\hline Participant & $\begin{array}{c}\text { Age } \\
(\mathbf{y r s})\end{array}$ & $\begin{array}{c}\text { Body } \\
\text { Mass }\end{array}$ & $\begin{array}{c}\text { Full Years } \\
\text { Competing }\end{array}$ & $\begin{array}{c}\text { Amateur } \\
\text { Record } \\
\text { W-L-D }\end{array}$ & $\begin{array}{c}\text { Professional } \\
\text { Record } \\
\text { W-L-D }\end{array}$ \\
\hline $\mathbf{1}$ & 27 & 69.2 & 6 & $4-1-0$ & $15-3-0$ \\
$\mathbf{2}$ & 20 & 71.7 & 1 & $1-1-1$ & $0-0-0$ \\
$\mathbf{3}$ & 28 & 77.3 & 2 & $2-0-0$ & $1-1-0$ \\
$\mathbf{4}$ & 28 & 63.7 & 6 & $3-0-0$ & $6-1-0$ \\
$\mathbf{6}$ & 26 & 62.4 & 4 & $3-3-0$ & $0-0-0$ \\
$\mathbf{7}$ & 21 & 68.9 & 1 & $2-0-0$ & $0-0-0$ \\
\hline Mean \pm SD & $24.6 \pm 3.5$ & $69.9 \pm 5.7$ & $3.1 \pm 2.2$ & N/A & N/A \\
\hline
\end{tabular}

Yrs; years, kg; kilograms, W; wins, L; losses, D; draws, N/A; non applicable, SD; standard deviation. 
"Extreme Rapid Weight Loss and Rapid Weight Gain Observed in UK Mixed Martial Arts Athletes Preparing for Competition" by Matthews JJ, Nicholas C

International Journal of Sport Nutrition and Exercise Metabolism

(c) 2016 Human Kinetics, Inc.

Table 2. Frequency analysis of the weight loss methods reported by the MMA athletes.

\begin{tabular}{|c|c|c|c|c|c|}
\hline RWL Method & $\begin{array}{c}\text { Always } \\
(\%)\end{array}$ & $\begin{array}{c}\text { Sometimes } \\
(\%)\end{array}$ & $\begin{array}{c}\text { Almost } \\
\text { Never } \\
(\%)\end{array}$ & $\begin{array}{l}\text { Never } \\
(\%)\end{array}$ & $\begin{array}{c}\text { Do Not Use } \\
\text { Anymore } \\
(\%)\end{array}$ \\
\hline $\begin{array}{l}\text { Gradual } \\
\text { Dieting }\end{array}$ & 86 & 0 & 14 & 0 & 0 \\
\hline $\begin{array}{l}\text { Skipping 1-2 } \\
\text { Meals }\end{array}$ & 29 & 14 & 43 & 14 & 0 \\
\hline Fasting & 14 & 57 & 0 & 14 & 14 \\
\hline $\begin{array}{l}\text { Restricting } \\
\text { Fluids }\end{array}$ & 86 & 14 & 0 & 0 & 0 \\
\hline $\begin{array}{l}\text { Increased } \\
\text { Exercise }\end{array}$ & 71 & 14 & 0 & 14 & 0 \\
\hline $\begin{array}{l}\text { Heated } \\
\text { Training } \\
\text { Rooms }\end{array}$ & 14 & 0 & 14 & 57 & 14 \\
\hline Sauna & 43 & 29 & 0 & 0 & 29 \\
\hline Hot Baths & 29 & 29 & 14 & 29 & 0 \\
\hline $\begin{array}{l}\text { Hot Salt } \\
\text { Baths }\end{array}$ & 71 & 14 & 14 & 0 & 0 \\
\hline $\begin{array}{c}\text { Training } \\
\text { Plastic Suits }\end{array}$ & 43 & 14 & 14 & 0 & 29 \\
\hline Spitting & 0 & 14 & 14 & 43 & 29 \\
\hline Laxatives & 0 & 14 & 29 & 29 & 29 \\
\hline Diuretics & 0 & 14 & 14 & 43 & 29 \\
\hline Diet Pills & 0 & 0 & 14 & 71 & 14 \\
\hline $\begin{array}{l}\text { Fat Burner } \\
\text { Supplements }\end{array}$ & 14 & 14 & 0 & 43 & 29 \\
\hline Vomiting & 0 & 0 & 0 & 71 & 29 \\
\hline $\begin{array}{l}\text { Water } \\
\text { Loading }\end{array}$ & 57 & 43 & 0 & 0 & 0 \\
\hline
\end{tabular}

